УДК 13.71

ББК 79.3

DOI 10.22455/2619-0311-2019-3-179-185

Николай Богданов

\author{
«Я должен видеть теми же глазами...» \\ Фронтовое письмо внука Ф.М. Достоевского \\ (Из фондов Государственного музея истории \\ российской литературы им. В.И. Даля)
}

\title{
Nickolay Bogdanov \\ "I Must See with the Same Eyes..." \\ A Letter from the Front by F.M. Dostoevsky's Grandson (From Collections of the V.I. Dal State Museum of the History of Russian Literature)
}

Об авторе: Николай Николаевич Богданов, психиатр, психолог и культуролог, Москва.

E-mail: bognick@mail.ru,bonn62@yandex.ru

Аннотация: Публикуемое письмо отражает черты биографии и личности младшего внука писателя, не терявшего связи с литературной жизнью даже в условиях военного времени. Позже он станет одним из самых деятельных исследователей и пропагандистов творчества своего деда - признанного классика мировой литературы.

Ключевые слова: Достоевский, биография, творческое наследие, семейное окружение.

Для цитирования: Богданов Н.H. «Я должен видеть теми же глазами...» Фронтовое письмо внука Ф.М. Достоевского // Достоевский и мировая культура. Филологический журнал. 2019. № 3(7). С.

DOI 10.22455/2619-0311-2019-3-179-185

About the author: Nickolay N. Bogdanov, psychiatrist, psychologist and culture researcher (Moscow).

E-mail: bognick@mail.ru,bonn62@yandex.ru

Abstract: The letter being published here reflects some biographical and personal features of the youngest Dostoevsky's grandson who didn't lose touch with the literary life even during wartime. Later he would become one of the most 
active researchers and promoters of his grandfather's work as a true classic of world literature.

Key words: Dostoevsky, biography, artistic heritage, family surroundings.

For citation: Bogdanov N.N. "I Must See with the Same Eyes..." A Letter from the Front by F.M. Dostoevsky's Grandson (From Collections of the V.I. Dal State Museum of the History of Russian Literature). Dostoevsky and World Culture, Philological journal, 2019, No 3 (7), pp.

DOI 10.22455/2619-0311-2019-3-179-185

В обширном эпистолярном наследии Андрея Фёдоровича Достоевского (1908-1968) - далеко ещё не опубликованном во всей должной полноте и, уж тем более, с должной полнотой не осмысленном - письма с фронта занимают особое место. Правда, известно их совсем не много; значительная часть не разыскана, некоторые, в том числе и фронтовые письма к жене, в настоящее время утрачены ${ }^{1}$. Публикуемое ниже адресовано Нине Захаровне Метельской (1893-1956) - в 1930-е гг. сотруднице, а с 1940 по 1955 гг. заведующей Московским музеем Ф.М. Достоевского, преемнице на этом посту его организатора и первого директора Веры Степановны Нечаевой (1893-1979). О контактах Андрея Фёдоровича с Музеем на Божедомке в довоенное время известно мало. По всей видимости, впервые он побывал здесь в апреле 1935 г., о чём свидетельствуют две фотографии, запечатлевшие внука писателя в «жёлтой гостиной» казённой квартиры его прадеда - лекаря Мариинской больницы Михаила Андреевича Достоевского. Первая - групповой снимок, где, кроме А.Ф. Достоевского, присутствуют Н.З. Метельская и В.С. Дороватовская-Любимова ${ }^{2}$. Пояснительная запись на второй, сохранившейся в домашнем архиве Ф.Ф. Бережкова, сделанная его рукой, как раз и позволяет установить дату․․ Вероятнее всего,

1 Свидетельство московского журналиста А.Б. Борина, у которого хранились эти письма после ухода внука писателя из семьи.

2 Известны два оттиска, один из которых - в собрании Государственного музея истории российской литературы им. В.И. Даля, второй - в фондах Петербургского музея-квартиры Ф.М. Достоевского.

3 Фотографии опубликованы: [Богданов, 2014, с. 218.] 
и сам визит состоялся по инициативе и при посредничестве этого человека - большого друга семьи Достоевских, много сделавшего и в память ярчайшего из её представителей. Недаром В.С. Нечаева в дарственной надписи на экземпляре вышедшего в 1934 г. путеводителя по Музею Ф.М. Достоевского, именовала Ф.Ф. Бережкова его «почетным сотрудником» ${ }^{4}$. Так и он станет подписывать свои письма к ней

Фёдор Фёдорович Бережков (1888-1943) - философ, филолог и психолог, один из лучших знатоков биографии и творчества Ф.М. Достоевского, человек сложной, даже трагической судьбы ${ }^{6}$. В 1921 г. его вынудят покинуть Московский университет, подготовленный им ещё до Октябрьской революции курс «Введение в изучение Достоевского (философские и психологические проблемы творчества)» так и не будет прочитан. Единственная печатная работа - «Достоевский на западе (1916-1928)», до сих пор не потерявшая своего значения - опубликована Ф.Ф. Бережковым в 1928 г. в Трудах Государственной академии художественных наук [Бережков, 1928]. В феврале 1942 г. он выступит на Божедомке с докладом по случаю 61-й годовщины со дня смерти писателя. Увы, меньше чем через год этого незаурядного, но практически не реализовавшегося исследователя не станет. «Что нашли для Музея от Фёдора Фёдоровича?» - интересуется А.Ф. Достоевский в публикуемом ниже письме. Вопрос звучит интригующе. Ведь ещё в 1934 г. Ф.Ф. Бережков обращался к В.С. Нечаевой по поводу одного из имеющихся у неё экспонатов: «А я забыл: книга, мной переданная, теперь у Вас, в музее?» [Богданов, Бережков, 2012, с. 342]. Речь идёт о церковной метрической книге с записью о рождении и крещении Ф.М. Достоевского. Так, может быть, этот вклад был не единственным?

«Война - совсем не фейерверк, а просто трудная работа...» - писал в декабре 1942 г. Михаил Кульчицкий. (По странной иронии судьбы он покинет этот мир в один день с Ф.Ф. Бережковым.) «Сейчас [нам] значительно трудней, т.к. сидим в болоте, - как бы вторит поэту А.Ф. Достоевский. - Грязь, вода, отсутствие не только дорог, но даже тропинок. <...> Я по-прежнему уж два месяца на оперативн[ой] работе при штабе дивизии. Это рискованно, утомительно и крайне

\footnotetext{
4 Книга с автографом сохранилась в семейном архиве Бережковых.

5 Отдел рукописей Российской государственной библиотеки. Ф.792. Карт. 16. Ед. хр. 2.

6 Подробнее о Ф.Ф. Бережкове см.: [Богданов, Бережков, 2012, с. 339-346.]
} Л. 3. 
беспорядочно, т.к. вспышки деятельности [возникают] в зависимости от обстановки» ${ }^{7}$. Тем выразительнее факт: все фронтовые годы внуку писателя доставало сил думать о будущем Божедомки. «У меня есть несколько планов-предположений, косвенно и прямо связанных с Музеем», - делится он с Н.З. Метельской. К сожалению, сказать определённо, что имелось в виду, сейчас уже вряд ли возможно. Однако перед нами несомненная родовая черта Достоевских - борцовские качества. Не будь её - имели бы мы такого писателя, как Ф.М. Достоевский?

Упоминание в письме литературоведа Ореста Вениаминовича Цехновицера (1899-1941) свидетельствует о вовлеченности А.Ф. Достоевского в литературную жизнь Ленинграда. Стоит подчеркнуть: об этой стороне его деятельности - инженера-конструктора автомобильной и тракторной промышленности, технаря «до мозга костей» - вообще ничего не известно. Во второй половине 1930-х гг. О.В. Цехновицер заведовал отделом рукописей Института русской литературы, позже был его учёным секретарём, перед самой войной преподавал в Ленинградском университете. Его перу принадлежит несколько литературоведческих работ, в том числе и диссертация «Путь Ф.М. Достоевского», оставшаяся незащищённой. Судя по всему, именно её судьбой и интересуется внук писателя. Летом 1941 г. Орест Владимирович, действительно, уйдёт политруком на флот и погибнет 28 августа того же года, участвуя в эвакуации военных кораблей из Таллинна. В 1942 г. по инициативе Вс. Вишневского его посмертно наградят орденом Красного Знамени.

Письмо А.Ф. Достоевского к Н.З. Метельской хранится в фондах Государственного музея истории российской литературы им. В.И. Даля (Ф. 81. Оп. 1. Ед. хр. 104. Л. 1). Фрагмент из него дважды публиковался нами ранее с некоторыми разночтениями [Богданов, 2009, с. 226; Богданов, 2011, с. 219-220]. Но что ж поделать, если Андрей Фёдорович «утомлял своим почерком» не только адресатов, но и последующих публикаторов и комментаторов его писем?

\footnotetext{
7 Письмо к Ф.Ф. Бережкову. 3 мая 1942 г. Архив Бережковых.
} 
Многоуважаемая Нина Захаровна!

Получил Ваше письмо в канун своего дня рождения ${ }^{8}$, сердечно благодарю Вас за внимание и память. Год назад я был в это время в Москве, но, проведя 10 дней на заводах, был настолько лишён свободного времени, что нигде и ни у кого не побывал (за искл[ючением] Бережковых, когда и узнал о смерти Фёдора Фёдоровича $\left.{ }^{9}\right)$. О Музее у меня были сведения, что он куда-то эвакуирован (в Сибирь) и все сотрудники выбыли с ним же ${ }^{10}$. Сообщённые теперь Вами сведения для меня и радостны и неожиданны; частенько думалось о Музее, ка[к] Вы знаете, что ранее, в мирное время с Музеем я связывался лишь эпизодически, а теперь, став солдатом, никакой реальной связи конечно не имею. И это очень жаль!

Конечно, Ваше письмо мне очень интересно и теперь возник целый ряд вопросов, на которые надеюсь получить ответы от Вас. Вот они:

Очевидно, в ближайшее время будет освобождена от фашистских захватчиков Старая Русса ${ }^{11}$, намечает ли Литерат[урный] Музей какой-либо выезд туда, для того чтобы определить судьбу дома Достоевского, и как немцы отнеслись к мемориальным местам, связанным с именем столь известного для них писателя? ${ }^{12}$

Предполагается ли официальное открытие Музея по весне, т.е. я хочу сказать, что будет ли оно соответственно отмечено в официально-торжественном порядке?

С Ник[олаем] Павл[овичем] Анциферовым ${ }^{13}$ мне, несомненно, очень желательно было бы свидеться, но прежде того, прошу сообщить мне подробнее о нём, начиная с его соц[иально]-демографических данных, коснуться его работ по Достоевскому прежде и дать сведения о его работе сейчас. Я его лично совсем забыл, либо

8 Внук писателя родился 10 февраля 1908 г., то есть в 27-ую годовщину со дня смерти Фёдора Михайловича.

9 Ф.Ф. Бережков скончался 19 января 1943 г. от затяжного воспаления лёгких.

103 мая 1942 г. А.Ф. Достоевский писал Ф.Ф. Бережкову: «Любимова выехала вместе с Музеем? - Если так, то прошу Вас ещё раз означить его адрес. Тот, что Вы прислали, я случайно уничтожил. Хотел бы с ним связаться (и как имя и отчество Любимовой?)». Письмо хранится в архиве Бережковых.

11 Город был освобождён 18 февраля 1944 г.

12 Мемориальный дом Ф.М. Достоевского чудом сохранился.

13 Анциферов Николай Павлович (1889-1958) - культуролог, основоположник литературного краеведения. 
совсем не знаю ${ }^{14}$. Жена ${ }^{15}$ обратила внимание на его статью в газете «Литература и искусство» (от 29.1) «Священная Земля» и тоже запрашивает меня о нём?

Какова судьба работ Цехновицера? С ним я прощался 14.6.[19]41 [г.] и примерно в ноябре [19]41 г. узнал о его гибели. Кстати же имеете ли Вы сведения о его гибели? Тогда он мечтал идти в подводный флот в качестве политработника, кажется, его в[оинское] звание было - полковой комиссар. Позднее узнал о разграблении квартиры-имущества Ореста Вениаминовича.

Где и что Любимова ${ }^{16}$, Вера Степановна [Нечаева], Волоцкой ${ }^{17}$, что нашли для Музея от Фёдора Фёдоровича (кстати, каково положение его семьи, т.к. от [его вдовы] Ольги Ксенофонтовны или [сына] Лёни ${ }^{18}$ я не получил ответа на своё последнее письмо $\left.{ }^{19}\right)$ ?

Кажется, я засыпал Вас вопросами, на которые буду обязательно ждать ответа. У меня есть несколько планов-предположений, косвенно и прямо связанных с Музеем. Но об этом в след[ующем] письме 20 - я и так утомил Вас своим почерком.

Жена и дочь ${ }^{21}$ здоровы. Я, возможно, скоро переменю свой адрес, а пока прошу писать по старому адресу, что на конверте.

Всего, всего доброго, ещё раз благодарю за внимание и память.

Уважающий Вас, А. Достоевский.

[Приписка на полях]. Ваше указание о фотографии выполню специальным снимком. Теперь же, чтобы Вы имели более вещественный привет с фронта, вкладываю этот обрезочек от фото.

14 Сведений о личном общении этих людей в предвоенный период не имеется.

15 Достоевская (в дев. Куршакова) Татьяна Владимировна (1909-1993) - библиограф, большую часть жизни проработала в Государственной библиотеке им. М.Е. Салтыкова-Щедрина (Ленинград).

16 Дороватовская-Любимова Вера Сергеевна (1888-1955) - писатель, литературовед; в 1930-е гг. - сотрудник московского музея Ф.М. Достоевского.

17 Волоцкой Михаил Васильевич (1893-1944) - антрополог, генетик; автор капитального труда «Хроника рода Достоевского» (1933). Известны два письма А.Ф. Достоевского к М.В. Волоцкому середины 1930-х гг.

18 Бережков Леонид Фёдорович (1925-2015) - в будущем врач-педиатр, доктор медицинских наук.

19 В архиве Бережковых это письмо отсутствует.

20 Такое письмо неизвестно.

21 Достоевская (по мужу Высогорец) Татьяна Андреевна (1937-2003) - в будущем инженер-технолог радиопромышленности. 


\section{Список литературы}

1. Бережков, 1928 - Бережков Ф.Ф. Достоевский на Западе (1916-1928) // Достоевский. Сборник статей. М.: Изд-во ГАХН, 1928. С. 277-326.

2. Богданов, Бережков, 2012 - Богданов Н.Н., Бережков Л.Ф. Из истории московского музея Ф.М. Достоевского // Достоевский и мировая культура. Альманах. 2012. Вып. 28. С. 339-346.

3. Богданов, 2011 - Богданов Н.Н. «Лица необщим выраженьем...» Родственное окружение Ф.М. Достоевского. М.: Старая Басманная, 2011. 354 с.

4. Богданов, 2014 - Богданов Н.Н. «Лица необщим выраженьем...» Родственное окружение Ф.М. Достоевского. 2-е изд. М.: Новый хронограф, 2014. 468 с.

5. Богданов, 2009 - Богданов Н.Н. Материалы к родословию Достоевских // Достоевский и современность. Материалы XXIII Международных Старорусских чтений 2008 года. Великий Новгород, 2009. С. 226.

\section{References}

1. Berezhkov F.F. Dostoevskij na Zapade (1916-1928) [Dostoevsky at the West (19161928)]. Dostoevsky. Sbornik statei [Dostoevsky. Collection of artciles]. Moscow, GAKhN Publ., 1928, pp. 277-326. (In Russ.)

2. Bogdanov N.N., Berezhkov L.F. Iz istorii moskovskogo museja Dostoevskogo [From the history of Moscow Dostoevsky Museum]. Dostoevskii i mirovaia kultura, vol. 28, 2012, pp. 339346. (In Russ.)

3. Bogdanov N.N. "Litsa neobshim vyrazhejem..." Rodstvennoe okruzhenie Dostoevskogo [“Uncommon countenance..." Dostoevsky's family environment]. Moscow, Staraya Basmannaya Publ., 2011. 354 p. (In Russ.)

4. Bogdanov N.N. "Litsa neobshim vyrazhejem..." Rodstvennoe okruzhenie Dostoevskogo [“Uncommon countenance..." Dostoevsky's family environment], $2^{\text {nd }}$ ed. Moscow, Novyj hronograf Publ., 2014. 468 p. (In Russ.)

5. Bogdanov N.N. Matherialy k rodoslowiju Dostoevskich [Materials to Dostoevsky's Genealogy]. Dostoevskii i sovremennost' [Dostoevsky and the modern age]. Materials of the XXIII International Readings in Staraya Russa. Veliky Novgorod, 2009, p. 226. (In Russ.) 